\title{
WEB-BASED INSTRUMENTS FOR STRENGTHENING SUSTAINABLE REGIONAL DEVELOPMENT IN THE ALPS
}

Axel Borsdorf, Oliver Bender, Fides Braun, Andreas Haller

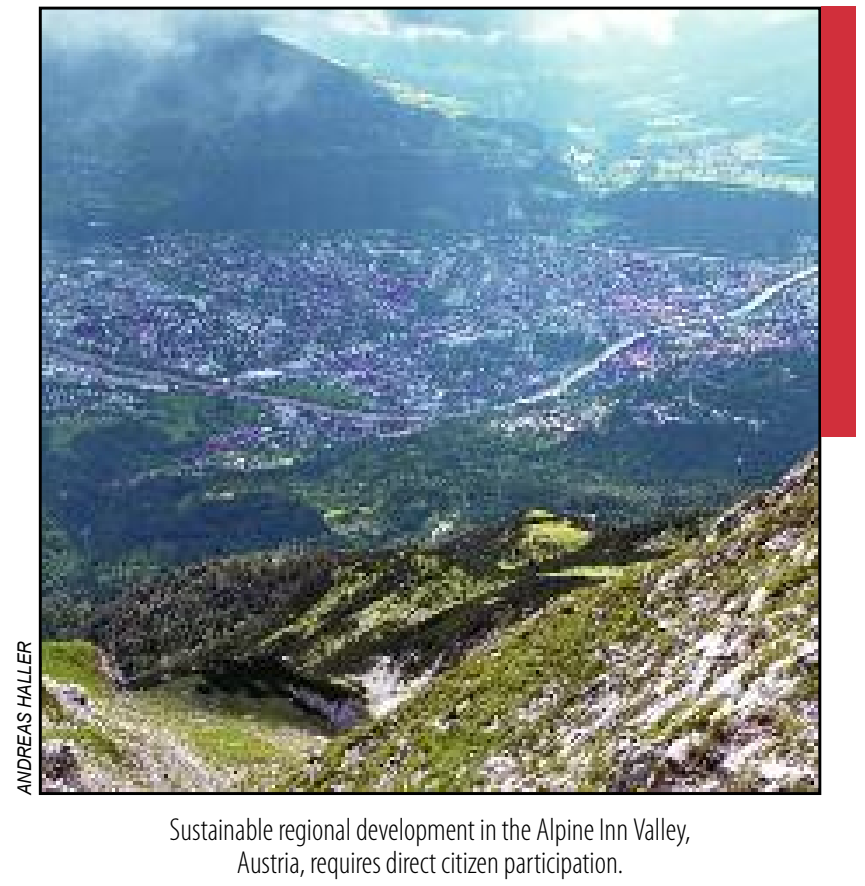




\section{Web-based instruments for strengthening sustainable regional development in the Alps}

DOI: http://dx.doi.org/10.3986/AGS.897

UDC: 913:502.131.1:004.738(234.3)

COBISS: 1.01

ABSTRACT: Web-based information and communication technologies enable the inclusion of all stakeholders in sustainable regional development and raise hopes that these processes will be accomplished from the bottom up and with broad public participation. This article synthesizes, presents, and critically discusses solutions for the Alps that use web 2.0 technologies, in particular: (a) GALPIS and DIAMONT with databases and an interactive webGIS, (b) mountain.TRIP as an efficient communication and information system to link research with practice, and (c) mountain wikis as tools for collaborative regional planning and development. The results indicate that new information and communication instruments enhance the implementation, promotion, assessment, and steering of sustainable regional development in the Alps.

KEYWORDS: geography, regional development, web 2.0, social media, Alps

The article was submitted for publication on August 21 $1^{\text {st }}, 2014$.

\section{ADDRESSES:}

\section{Axel Borsdorf}

Institute for interdisciplinary mountain research, Austrian academy of sciences

Technikerstrasse 21a, Innsbruck, A - 6020, Austria

E-mail: axel.borsdorf@oeaw.ac.at

\section{Oliver Bender}

Institute for interdisciplinary mountain research, Austrian academy of sciences Technikerstrasse 21a, Innsbruck, A - 6020, Austria

E-mail: oliver.bender@oeaw.ac.at

\section{Fides Braun}

Institute for interdisciplinary mountain research, Austrian academy of sciences Technikerstrasse 21a, Innsbruck, A - 6020, Austria

E-mail: fides.braun@gmail.com

\section{Andreas Haller}

Institute of geography, University of Innsbruck

Innrain 52, Innsbruck, A - 6020, Austria

E-mail: andreas.haller@uibk.ac.at 


\section{Introduction}

At the first Alpine conference in Berchtesgaden in 1989, the Alpine countries, together with the European Economic Community, the precursor to the European Union, declared their intent to create a framework convention for development in the Alps. The convention was signed by the ministers of the environment of the Alpine countries in Salzburg in 1991. This was the start of the Alpine Convention, which was ratified by the eight Alpine countries in subsequent years.

The basic ideas of the nine implementing protocols to date are cross-border support for sustainable regional development in the Alps under conditions of climate change and globalization, as well as increasing international competitiveness and the attractiveness of the Alps. Despite the successes of the Alpine Convention, the slow ratification of the protocols by the member states and the protracted negotiations demonstrate the difficulties of implementing these ideas at a political level. In 2000 a structural fund was therefore created to support transdisciplinary research projects within INTERREG IIIB: the Alpine Space Programme. In 2014 it entered its third funding period.

This article focuses on the results of selected projects (from the Alpine Space Programme or other funding sources) that have made use of the rapidly improving options provided by modern internet information and communication technologies. These projects are presented below and their scope for promoting sustainable regional development is discussed. The aims are to synthesize and present research projects carried out from 2000 to 2014 and, based on the authors' experiences, critically discuss their scope for promoting sustainable regional development.

The central hypothesis of this article is that new information and communication tools based on web 2.0 technologies may increase valuable bases for implementing, promoting, and steering sustainable regional development in the Alps.

The presentation is mainly based on the publications created within these projects, available documentation on the internet, and the products, complemented by general literature on these technologies. The study uses inductive logic: it first discusses the challenges to sustainability within the Alps, then presents individual solutions, and concludes with an overview.

\section{Sustainable regional development: A challenge for the Alps}

Soon after the publication of the report Our Common Future by the World Commission on Environment and Development (the Brundtland Commission) in 1987 (WCED 1987), sustainable development became a new paradigm, including in the Alps. Since then, the policy of the Alpine Convention has been dedicated to this overall goal based on environmental compatibility, social coherence, and economic growth for long periods of time. In response to critical discussions (Spehr 1996; Bergstedt 2005), some authors added a cultural dimension (safeguarding cultural diversity) and a political dimension (safeguarding political stability) to the three pillars (Hodge 1997). In the German-speaking countries, the alternative term Zukunftsfähigkeit ('future-proof'; BUND and Misereor 2002) came into use, not least of all under the influence of the German parliament study commission titled Protecting mankind and the environment.

The pairing "global change and regional sustainability« evolved from the impression that global developments (climate change and globalization) represent a particular threat to sustainable development (Hahne 2010; Coy and Stötter 2013). It included the realization that sustainability strategies could primarily succeed at the local and regional levels. In contrast, concepts of "glocalization « seek to understand globalization and localization as complementary processes on a micro-meso-macro scale (Robertson 1998). For the Alps, this means that regional sustainability must take into account factors of global change. To this end, new globally available information and communication technologies can be effectively used to exchange data, insights, best practices, and research results. Sustainable regional development is thus based not only on political programs but also on research and close communication between researchers and practitioners. The multiannual program of the Alpine Convention and the research strategy of the International Committee on Research in the Alps (ISCAR; see Borsdorf et al. 2008) defined sustainability as the main challenge for development in the Alps, and Braun and Borsdorf (2014) added capacity building, governance, and management. This objective includes powerful information and communication instruments. 


\section{Applying web-based information and communication technologies}

Before 1990, scientifically validated information was mostly available in research volumes, journal articles, or encyclopedias. Communication among researchers was limited to team discussions, postal correspondence, and (more rarely) replies published in journals. In the early 1990s, almost concurrently with the emergence of sustainable regional development as an objective, the development of the World Wide Web (WWW) created a basis for new options. The WWW allowed faster multilateral communication by e-mail, increasingly more journals were published online (some of them with open access), and data and maps could be published on the web as databases or via map servers; interaction by the users, however, was limited to data searches and modification of visualization. Examples are the Tirol Atlas (http://tirolatlas.uibk.ac.at/; regional scale), the ÖROK Atlas (http://www.oerok-atlas.at/; national) in Austria, and the ESPON mountain regions maps of Europe (http://atlas.espon.eu/).

It was only at the beginning of the twenty-first century that new options were created for citizen-public involvement, user-steered webGIS instruments for generating content, and dynamic communication between researchers, practitioners, and the public. Figure 1 provides an overview on the appearance and functionality of information and communication over the course of time.

Within spatial planning and development, three main web-based technologies are currently in use and accessible via the internet and a browser - to support the generation, provision, and exchange of information to enable sustainable regional development. The first is the individual query, analysis, and graphic representation of spatial data and information from databases via browser-based applications (webGIS). The second is leveraging new options emerging from the creation of digital social networks (social media), and the third is the increased use of wiki technology (a content management system) for providing and managing information relevant to a particular theme.

What makes webGIS applications particularly promising in the context of the public's participation and regional development is the fact that they allow users to call up geographical information via a browser and internet access, and to analyze and display it in line with their individual interests without having to purchase expensive geodata or costly GIS software. The frequently emphasized distinction between web mapping as focusing on data display and webGIS as focusing on data analysis (Neumann 2008) is becoming increasingly blurred because newer applications often combine cartographic and analytical functions. In collaborative planning and development, the combination of webGIS and traditional forms of participatory decision-making (Dragićević and Balram 2004) has proved to be a very promising approach to sustainable development.

Social media are also beginning to play a larger role in spatial planning and development (Deddens 2011), both as a source of geographical information (Massa and Campagna 2014) - just think of localizing digital photographs or analyzing user-generated texts by geographical content (social media geographic information, SMGI) - and as a tool for identifying, including, and involving all stakeholders in decision-making processes (Bizjak 2012). Krätzig and Warren-Kretzschmar (2014) list the advantages offered by social networks as the opportunity to define the topics that matter most to the public, to gather local knowledge

Table 1: Matrix of information and communication systems over the course of time (source: authors)

\begin{tabular}{|c|c|c|c|c|c|}
\hline & $\begin{array}{l}\text { Scientific } \\
\text { information }\end{array}$ & $\begin{array}{c}\text { Personal } \\
\text { communication }\end{array}$ & $\begin{array}{c}\text { Data inquiry } \\
\text { and map display }\end{array}$ & $\begin{array}{c}\text { Unlimited } \\
\text { communication }\end{array}$ & $\begin{array}{c}\text { Participative } \\
\text { content generation }\end{array}$ \\
\hline Books, Articles & $x$ & & & & \\
\hline $\begin{array}{l}\text { Encyclopedias, Atlases, } \\
\text { Static Map Server }\end{array}$ & $\times$ & & & & \\
\hline Emails & & $x$ & & & \\
\hline $\begin{array}{l}\text { Databases, Dynamic } \\
\text { Map server }\end{array}$ & & & $x$ & & \\
\hline Social media, Wiki & & & & $x$ & $x$ \\
\hline \multirow[t]{2}{*}{ (Interactive) WebGIS } & & & & & $x$ \\
\hline & before 1990 & \multicolumn{2}{|c|}{$1990-2000$} & \multicolumn{2}{|c|}{ after 2000} \\
\hline
\end{tabular}


about the current state of a region, to identify opinions and development alternatives, and to encourage direct exchange between the people involved.

Another possibility of using web-based technologies for sustainable regional development is the creation of wikis on specific themes. Here the focus is on the joint creation, arrangement, and linking of written entries. Wiki technology (Leuf and Cunningham 2001) offers a comparatively simple content management system to do this. The concept aims to encourage as many users as possible to contribute to wiki entries, to categorize them, and to link them to other entries. The knowledge shared on wikis should in theory not be evaluated by chosen experts, but rather the quality of the entries should be secured by the participants themselves, who will immediately correct wrong information and discuss controversial material on a dedicated discussion page.

These digital tools are often mentioned in connection with buzzwords such as e-democracy or geocitizenship (Rotondo and Selicato 2011; Atzmanstorfer et al. 2014). Fredericks and Foth (2013) sum up their potential as the opportunity to:

- Integrate people that are physically unable to attend civic meetings in regional development processes;

- Engage younger people through new media to participate in decision-making processes;

- Offer stakeholders that decline personal contact with experts an option for participation;

- Monitor, analyze, and enhance public participation in planning processes.

In this context, Mandarano et al. (2010) speak of a new, digital, social capital that is evolving through the use of web-based information and communication technologies in collaborative regional planning and development. At the same time, critical voices are being raised about the unthinking application of web-based technologies in spatial planning and development. Elwood (2010) lists the main points of criticism in the current debate as the social and political constructedness of geodata, the knowledge policy concerning spatial information, and the role of geotechnologies and social media in monitoring and influencing "geocoded « citizens that continuously leave traces in digital space. Moreover, far too little is still known about how effectively the results from web-based public participation are being integrated into actual spatial development concepts and later implemented in practice (Mandarano et al. 2010). From their own experience, Kelly et al. (2012) therefore rightly point out that most web-based approaches to collaborative planning and development are still top-down measures. They do not stem from the public's desire for participation, but from a political order issued to experts to involve as many parties affected as possible.

\section{Solutions based on web 2.0 technologies}

\subsection{DIAMONT and GALPIS}

The first georeferenced database in the world with GIS functionality for the Austrian part of the Alps, which allowed web-based use of free calculation and free map design, was the GALPIS-Web System (Bender and Pindur 2003; Bender et al. 2010), implemented in 2003. It contains 1,300 variables, is thematically free, and follows an inductive-explorative logic. It includes data on ecology, biodiversity, demography, agriculture, tourism, cultural landscapes, and the human habitat. The data from 1971 to 2001 were temporally and spatially harmonized. Raster and real-space data were recalculated at the municipal level (LAU 2). The real strength of GALPIS-Web is its analytical functionality: through the free combination of all variables, the system even allows multitemporal (time section or change maps) and multithematic analyses: examples include location optimization, complex analyses (e.g., degree of urbanization of a municipality), and the creation of indicators (e.g., sustainability index or provision index). One highlight is the free choice of map design (Figure 2) in terms of color and signature, labeling, zooming, shading, or reference space (municipality or permanent settlement area). Examples can be found in Borsdorf (2005).

DIAMONT offers a similar database for the entire Alps (Borsdorf et al. 2008). Here, too, the municipality is the spatial unit of reference. Themes include natural space, the environment, society (including demography, education, and participation), and the economy. Complex indicators can be calculated from these basic data. However, this is purely a database linked to further data on spatial control instruments at the international, national, regional, and local levels, as well as to best-practice examples. The DIAMONT team created an atlas of the Alps (Tappeiner et al. 2008), and the mountain.TRIP project provides a tutorial on simplified use of the DIAMONT database (mountain.TRIP 2014). 


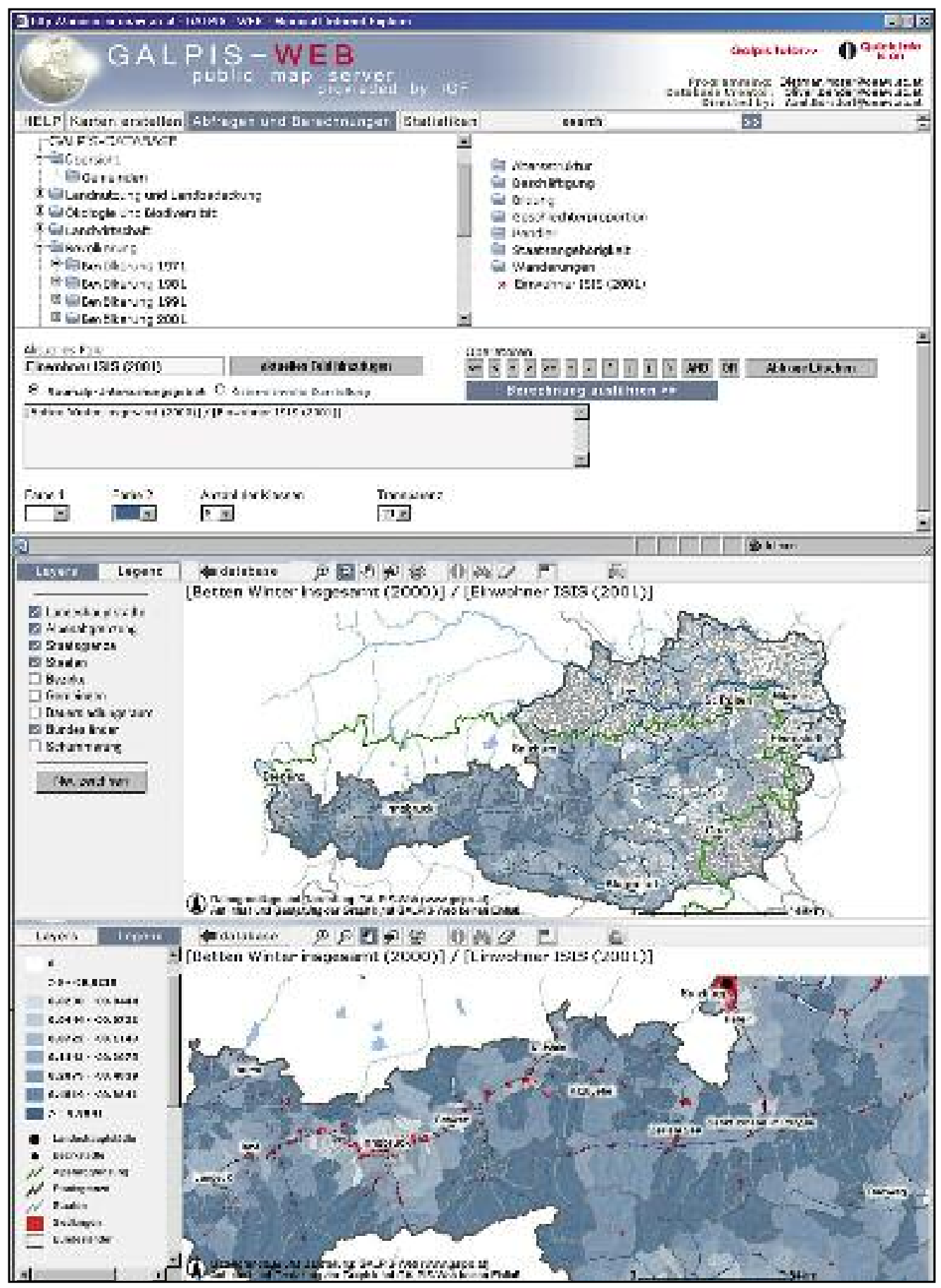

Figure 2: GALPIS-Web allows the graphic display of user-generated indicators (http://www.galpis.at) (Source: Galpis 2014). 


\subsection{Mountain.TRIP}

The EU 7FP project mountain.TRIP (Mountain.TRIP 2014) used the entire spectrum of web 2.0-based technologies to link research with practice and to create an efficient communication and information system (Braun 2010). It includes short videos (published on YouTube; mountain.TRIP 2011), a communication platform, web-based posters and leaflets, tutorials, manuals, teaching tools, news flashes, a project database with an interactive map, a researcher database, job announcements, and a wiki-type information set. The manual is available in five languages and seeks to show practitioners and researchers how to find results and data on European mountain areas on the internet (Borsdorf et al. 2011). However, the wiki developed there (mountain.WOCUR) does not yet offer full wiki functionality.

\section{Examples of mountain wikis}

Within the context of sustainable regional development, wikis are particularly well suited to providing transformation knowledge because the information offered is not just consumed by practitioners but also generated and checked. Research results find their way to users, but users' insights also find their way back to researchers. In this way an enhanced exchange between research and practice is taking place that is urgently needed to achieve sustainable regional development.

Within mountain research, examples already exist on how wikis can be built as tools for collaborative regional planning and development. The Mountain.TRIP project, funded in the EU's Seventh Framework Programme from 2009 to 2011 (Braun 2010), is already completed. It included the information and communication platform mountain.WOCUR (a wiki for capitalizing useful research). In 2013 and 2014, another wiki was implemented within the Alpine Space Programme's WIKIAlps project (Marzelli 2014), also EU-funded. It makes Alpine research results available in a brief and easily comprehensible format.

The web platform mountain. WOCUR aims to support researchers in communicating their findings to selected stakeholders. The content is divided into four categories. Entries in the »Guidelines « category help in developing a communication strategy, offer orientation in defining a target audience, and show researchers how to assess the success of their communication. Entries in the "Examples« and "Lessons Learned « categories illustrate possible approaches and offer options for making one's own experiences useful for others. The »Background Knowledge « category in mountain. WOCUR contains explanations of terms for better understanding of technical or methodological terms.

In contrast, WIKIAlps aims to support the transnational application of national research results to make results from individual Alpine countries easier to understand and usable for political decision-makers, researchers, and businesspeople throughout the Alps. To this end, WIKIAlps applies three different perspectives: first, the project perspective, which analyses and reorganizes the results of research projects; second, the policy perspective, which identifies and tries to understand political and planning challenges and needs on the basis of transnational and national documents; and, third, the stakeholder perspective, which identifies and analyses institutional stakeholders.

Although both projects use wiki technology in their technical implementation, they differ in their intended usage. The mountain.WOCUR project offers communication knowledge in an attempt to improve the exchange of insights between science and practice. This instrument cannot be changed by users; rather, it is a kind of online encyclopedia. In contrast, WIKIAlps focuses on preparing concrete project results on sustainable development within the Alps and promoting their use. It is a genuine wiki and relies on its content not just being read but also updated, amended, and expanded by its users.

\section{Conclusion: The contribution of web-based instruments to promoting sustainable regional development in the Alps}

From the insights gained so far with web-based information and communication technologies within the Alps (Figure 3), it can be said that they represent a major step forward on the path to including all stakeholders in sustainable regional development. So far the central hypothesis of this article appears to be proved: new information and communication instruments enhance the implementation, promotion, assessment, 
and steering of sustainable regional development in the Alps. Web 2.0 technologies greatly expand the options for disseminating information and for communication between researchers, practitioners, and the public. Another considerable advantage is improved participation in decision-making processes: with the aid of the new instruments, non-experts can now not only gain information but also process data themselves and become involved in improving available information. Technologies that allow stakeholders to not only consume information but also generate it raise hopes that these processes can be carried out bottom-up and with broad public involvement. Approaches like that of WIKIAlps may thus be considered a milestone in the ongoing enhancement of collaborative regional planning and development. However, the possibilities have by no means been fully explored yet. Future challenges will mainly be to maintain the new participation tools beyond the development phase, to improve them further, and to ensure their usefulness for the wider public in the longer term.

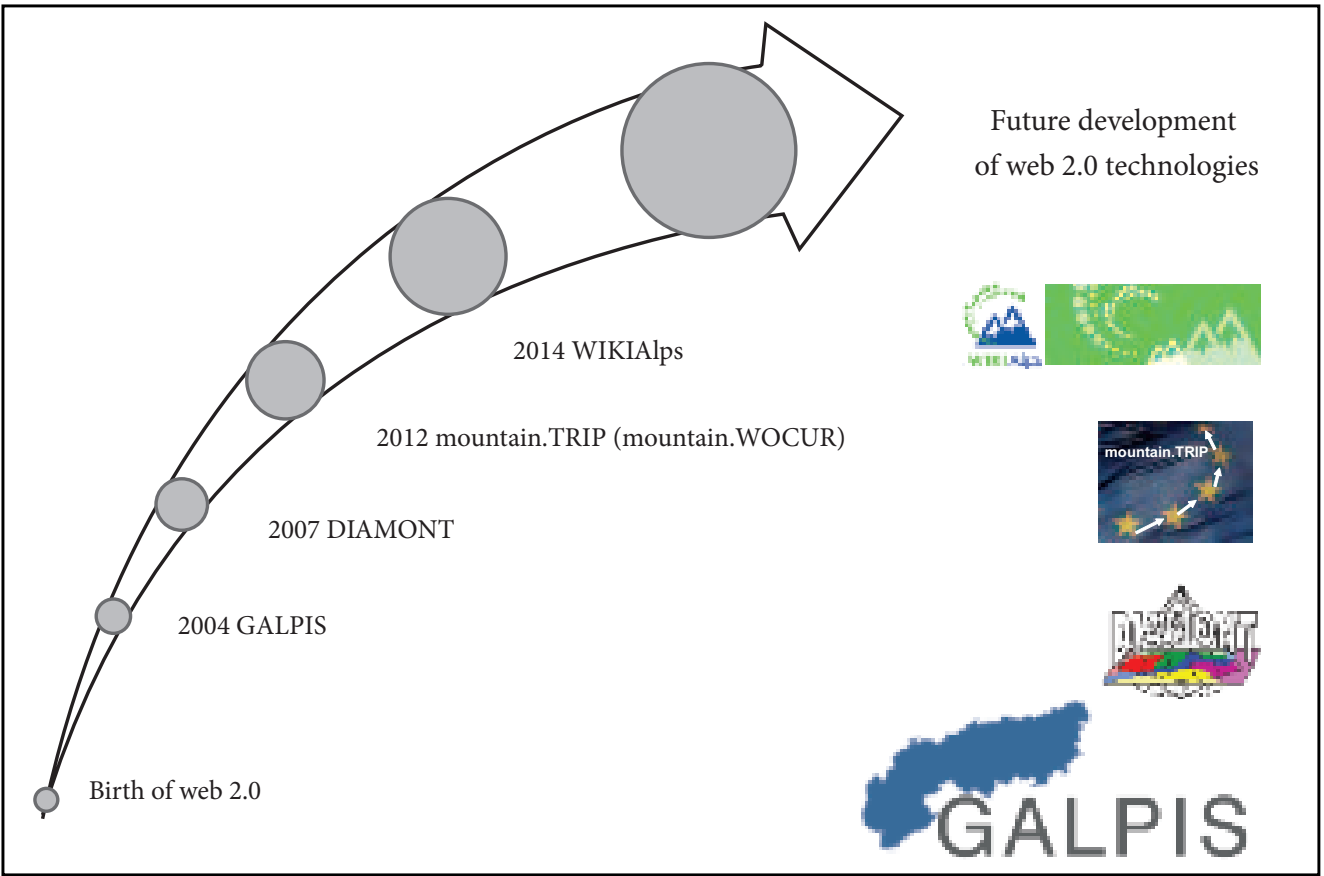

Figure 3: Development of instruments based on web 2.0 technologies in the Alps.

\section{References}

Atzmanstorfer, K., Resl, R., Eitzinger, A., Izurieta, X. 2014: The GeoCitizen-approach: community-based spatial planning - an Ecuadorian case study. Cartography and geographic information science 41-3. DOI: http://dx.doi.org/10.1080/15230406.2014.890546

Bender, O., Borsdorf, A, Heinrich, K. 2010: The interactive alpine information system GALPIS. Challenges for mountain regions, Tackling complexity. Vienna. Internet: www.mountainresearch.at/images/ Publikationen/Sonderband/bender-borsdorf-heinrich.pdf (4.8.2014).

Bender, O., Pindur, P. 2003: »RAUMALP « und »GALPIS - ein Geoinformationssystem für die (österreichischen) Alpen. Angewandte Geographische Informationsverarbeitung XV, Beiträge zum AGIT-Symposium Salzburg. Heidelberg.

Bergstedt, J. 2005: Nachhaltig, modern, staatstreu? Staats- und Marktorientierung aktueller Konzepte von Agenda 21 bis Tobin Tax. Frankfurt. 
Bizjak, I. 2012: Improving public participation in spatial planning with Web 2.0 tools. Urbani izziv 23-1. DOI: http://dx.doi.org/10.5379/urbani-izziv-en-2012-23-01-004

Borsdorf, A. (ed.) 2005: Das neue Bild Österreichs, Strukturen und Entwicklungen im Alpenraum und den Vorländern. Vienna.

Borsdorf, A., Scheurer, T., Psenner, R. 2008: Global change in the Alps and the multi-annual work programme of the Alpine Convention in the ISCAR perspectives. Le Alpi che cambiano: Nuovi abitanti, nuove culture, nuovi paesaggi. Udine.

Borsdorf, A., Tappeiner, U., Tasser, E. 2008: Introduction. Alpenatlas - Atlas des Alpes - Atlante delle Alpi Atlas Alp - Mapping the Alps, Society - Economy - Environment. Vienna.

Borsdorf, A., Braun, F., Deddens, L. 2011: mountain.SEARCH, Europäische Gebirgsforschung im Internet, Ein Handbuch für die Suche nach den Resultaten. Bern. Internet: www.mountaintrip.eu/mountaintrip-communication-products/mountainsearch.html (4. 8.2014).

Braun, F. 2010: Closing the gap between science and practice, Mountain.TRIP - an EU project coordinated by IGF. Challenges for mountain regions, Tackling complexity. Vienna. Internet: www.mountainresearch.at/ images/Publikationen/Sonderband/25_braun.pdf (4.8.2014).

Braun, V., Borsdorf, A. 2014: Mountains and their grand challenges. Bridges 40.

BUND, MISEREOR (eds.) 2002: Wegweiser für ein zukunftsfähiges Deutschland. Munich.

Coy, M., Stötter, J. 2013: Die Herausforderungen des Globalen Wandels. Forschen im Gebirge - Investigating the Mountains - Investigando las montañas, IGF-Forschungsberichte 5. Vienna.

Deddens, L. 2011: Social media in science. Eco.mont 3-2. DOI: http://dx.doi.org/10.1553/eco.mont-3-2s49

Deutscher Bundestag (ed.) 1998: Abschlussbericht der Enquete Kommission »Schutz des Menschen und der Umwelt - Ziele und Rahmenbedingungen einer nachhaltig zukunftsverträglichen Entwicklung «. Berlin.

Dragićević, S., Balram, S. 2004: A Web GIS collaborative framework to structure and manage distributed planning processes. Journal of geographical systems 6-2. DOI: http://dx.doi.org/10.1007/s10109-004-0130-7

Elwood, S. 2010: Geographic information science: emerging research on the societal implications of the geospatial web. Progress in human geography 34-3. DOI: http://dx.doi.org/10.1177/0309132509340711

Galpis - dem Geographischen Alpeninformationssystem. Internet: http://www.galpis.at (15.12.2014)

Fredericks, J., Foth, M. 2013: Augmenting public participation: enhancing planning outcomes through the use of social media and web 2.0. Australian planner 50-3. DOI: http://dx.doi.org/10.1080/07293682.2012.748083

Hahne, U. (ed.) 2010: Globale Krise - Regionale Nachhaltigkeit, Handlungsoptionen zukunftsorientierter Stadt- und Regionalentwicklung. Detmold.

Hodge, T. 1997: Toward a conceptual framework for assessing progress toward sustainability. Social indicators research 40. DOI: http://dx.doi.org/10.1023/A:1006847209030

Kelly, M., Ferranto, S., Lei, S., Ueda, K., Huntsinger, L. 2012: Expanding the table: The web as a tool for participatory adaptive management in California forests. Journal of environmental management 109. DOI: http://dx.doi.org/10.1016/j.jenvman.2012.04.035

Krätzig, S., Warren-Kretzschmar, B. 2014: Using interactive web tools in environmental planning to improve communication about sustainable development. Sustainability 6. DOI: http://dx.doi.org/10.3390/su6010236

Leuf, B., Cunningham, W. 2001: The wiki way, Collaboration and sharing on the internet: Quick collaboration on the web. Boston.

Mandarano, L., Meenar, M., Steins, C. 2010: Building social capital in the digital age of civic engagement. Journal of planning literature 25-2. DOI: http://dx.doi.org/10.1177/0885412210394102

Marzelli, S. 2014: EU-Projekt WIKIAlps verknüpft INTERREG-Projektergebnisse für die Nutzer. ANLiegen Natur 36-1.

Massa, P., Campagna, M. 2014: Social media geographic information: Recent findings and opportunities for smart spatial planning. TeMA - Journal of land use, mobility and environment. DOI: http://dx.doi.org/ $10.6092 / 1970-9870 \% 2 \mathrm{~F} 2500$

mountain.TRIP 2011: Welcome to mountain.TUBE. Internet: https://www.youtube.com/user/mountaintripeu (4.8.2014).

mountain.TRIP 2014: A screenshot tutorial for the DIAMONT database: indicators and instruments of sustainable regional development in the Alps. Internet: http://www.mountaintrip.eu/mountaintripcommunication-products/diamont-screenshot-tutorial.html (4.8.2014). 
Neumann, A. 2008: Web mapping and web cartography. Encyclopedia of GIS. Berlin. DOI: http://dx.doi.org/ 10.1007/978-0-387-35973-1_1485

Pascolini, M. (ed.) 2008: Le Alpi che cambiano: Nuovi abitanti, nuove culture, nuovi paesaggi. Udine.

Robertson, R. 1998: Glokalisierung: Homogenität und Heterogenität in Raum und Zeit. Perspektiven der Weltgesellschaft. Frankfurt.

Rotondo, F., Selicato, F. 2011: E-democracy in collaborative planning: A critical review. Computational science and its applications - ICCSA 2011. Berlin. DOI: http://dx.doi.org/10.1007/978-3-642-21887-3_16

Spehr, C. 1996: Die Ökofalle. Nachhaltigkeit und Krise. Vienna.

Tappeiner, U., Borsdorf, A., Tasser, E. (ed.) 2008: Alpenatlas - Atlas des Alpes - Atlante delle Alpi - Atlas Alp - Mapping the Alps, Society - Economy - Environment. Vienna.

WCED - World commission on environment and development 1987: Our common future - Brundtland report. Oxford. Internet: www.un-documents.net/our-common-future.pdf (4.8.2014). 